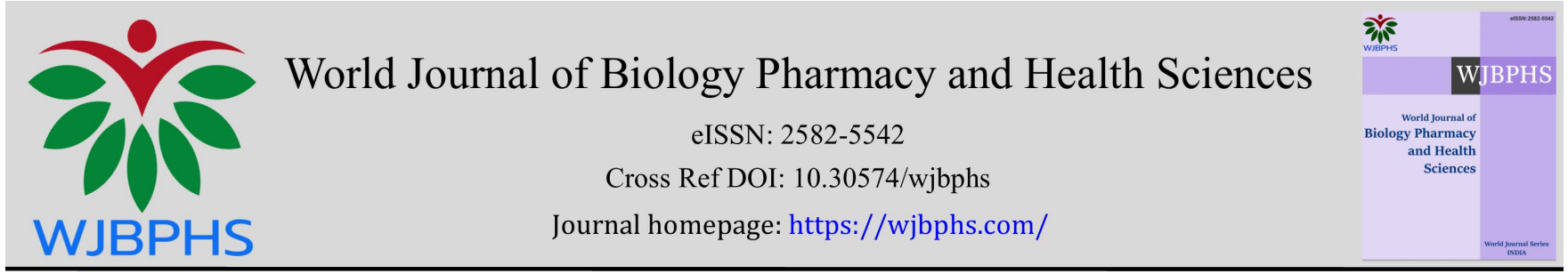

(RESEARCH ARTICLE)

\title{
Comparison of growth performance of live feed microalgae and rotifer (Brachionus $s p$.) under different feeding medium in outdoor culture condition
}

\author{
Nilufa Begum 1, ${ }^{*}$, M.N.S Mamun Siddiky ${ }^{1}$ and Shawon Ahmmed ${ }^{2}$ \\ ${ }^{1}$ Bangladesh Fisheries Research Institute, Shrimp Research Station, Bagerhat-9300, Bangladesh. \\ ${ }^{2}$ Bangladesh Fisheries Research Institute, Brackishwater Station, Paikgacha, Khulna-9280, Bangladesh.
}

World Journal of Biology Pharmacy and Health Sciences, 2021, 2021, 05(02), 025-032

Publication history: Received on 03 January 2021; revised on 09 February 2021; accepted on 11 February 2021

Article DOI: https://doi.org/10.30574/wjbphs.2021.5.2.0008

\begin{abstract}
Live feed is the basic food source and nutrient security for successful seed production of any commercially important aquaculture species of fishes, mollusks and crustaceans. Both plant and animal originated aquatic microscopic organisms are generally termed as live food. They are the basic food items in early stages (larval stage) of life cycle due to small sizes, easy digestibility and enriched in nutrients. The Nannochloropsis sp.; Nannochlorum sp. and Tetraselmis sp. are rich with relatively high content of essential fatty acids in comparison to other marine algae. Likelihood, the rotifer Brachionus sp. is ideal feed item for brackishwater finfish and mud crab larvae rearing due to its special features like rapid reproduction, slow movement, suitable size and easy digestion by the newly hatched larvae. The present study is the report on comparison of growth performance of live feed (microalgae and rotifer) in outdoor culture condition. The study was conducted at the hatchery complex of Bangladesh Fisheries Research Institute, Brackishwater Station, Paikgacha, Khulna. In outdoor culture condition the growth pattern obtained for three microalgae were Tetraselmis sp.> Nannochlorum sp.> Nannochloropsis sp. Highest average growth $6.87 \times 10^{6} \pm 1.97 \times 10^{6}, 6.91 \times 10^{6} \pm 1.69 \times 10^{6}$ and $6.23 \times 10^{6} \pm 1.53 \times 10^{6}$ was observed for Nannochloropsis sp., Nannochlorum sp. and Tetraselmis sp. respectively in trial 3. Average growth of rotifer (Brachionus sp.) found highest $189 \pm 18.10 \mathrm{ind}$./ml at combined media of yeast and microalgae and lowest growth $119.67 \pm 17.60 \mathrm{ind}$./ml noticed with baker's yeast media. Nannochloropsis sp. contains more energy among all microalgae but Tetraselmis sp. carry highest level of protein. The highest level of protein $56.3 \pm 0.18 \%$ found in rotifer enriched with microalgae+fish oil and lowest protein content noticed with microalgae enrichment media. So, research finding suggests that, treatment $\mathrm{T}_{3}$ would be the best recommendations for rotifer culture.
\end{abstract}

Keywords: Microalgae; Rotifer; Growth performance; Plastic jars; Bangladesh

\section{Introduction}

Live feeds are the chief item in the diet of cultured fish larvae and they are of particular significance when nurturing marine fish larvae of the altricial type. Altricial larvae are those that remain in a relatively immature state until the yolk sac is exhausted. At first-feeding the gastrointestinal system is still rudimentary, deficient of a stomach, and much of the protein digestion takes place in hindgut epithelial cells [1]. Such a digestive system is in most cases incompetent of processing articulated diets in a manner that allows survival and growth of the larvae comparable to those fed live feeds. In fact, despite recent progress in the development of inert diets for fish larvae [2-4], feeding of most species of interest for aquaculture still relies on live feeds during the early life stages. Brackishwater and marine hatcheries rely upon live foods as the main source of feeds for larvae of the target species being cultured. Though micro encapsulated and other inert diets have been developed for some commercial species (e.g. Penaeus monodon, Scylla serrata), there is still a

\footnotetext{
${ }^{*}$ Corresponding author: Nilufa Begum

Bangladesh Fisheries Research Institute, Shrimp Research Station, Bagerhat-9300.

Copyright (@ 2021 Author(s) retain the copyright of this article. This article is published under the terms of the Creative Commons Attribution Liscense 4.0.
} 
requirement for microalgae in the early stages and a combination of inert diets along with Artemia [5]. Live food organisms include all plants (phytoplankton) and animal (zooplankton) lives grazed upon by economically important fishes. Phytoplanktons are generally eaten by zooplankton. Thus, phytoplankton forms the basis of the food chain. Live foods are able to swim in water column and are constantly available to fish and shellfish larvae are likely to stimulate larval feeding response [6]. In the natural food web, zooplankton constitutes a major part of the diet for marine fish larvae and it is generally believed that copepods can meet the nutritional requirements of fish larvae [7]. Both plant and animal originated aquatic microscopic organisms, also termed as live food. Live feed is the basic food source and nutrient security for successful seed production of any commercially important aquaculture species of fishes, mollusks and crustaceans. They are the basic food items in early stages of life cycle due to small sizes, easy digestions and enriched in nutrients. Plant originated live food are known as phytoplankton (microalgae) are primary producers in the food web [8]. Whereas, animal originated microorganism are the secondary producer those grazes on phytoplankton. Hence, the live food supports for better survival and growth of fish, prawn and crustacean larvae. They are also considered as water purifiers since they consume soluble nutrients, bacteria and detritus. The culture and production of adequate nutritive live food organisms is considered as the heart of the hatchery for sustainable seed production [9]. However, production of available nutritive live foods is a challenge for the operation of hatchery in a sustainable manner. The Nannochloropsis sp.; Nannochlorum sp. and Tetraselmis sp. are rich with relatively high content of essential fatty acids in comparison to other marine algae [10]. Likelihood, the rotifer Brachionus sp. is ideal feed item for brackishwater finfish and mud crab larvae rearing due to the suitable sizes and easy digestion by the newly hatched larvae [11]. Very often, ordinary grown live feeds did not contain available nutrients to support the survival and growth of larvae, especially for the crustaceans. However, live feeds are needed to be enriched to enhance the qualitative and quantitative nutrients, especially the essential fatty acids of the HUFA's [12]. So, scaling up of live feed culture is the prime need for successful operation of seed production of commercially important marine and brackishwater species like, mullet (Mugil cephalus), parse fish (Chellon subviridis), mud crab (Scylla sp.), etc.

\section{Methodology}

\subsection{Study Location and Duration}

The proposed research was carried out in the live feed laboratory of Bangladesh Fisheries Research Institute (BFRI), Brackishwater station, Paikgacha, Khulna 2017-18. A 10 days experiment was implemented in the hatchery complex of Brackishwater Station at Paikgacha, Khulna. The experiment was repeated for thrice. Performance of live feed were evaluated from the cell density and nutrient content especially proximate composition and levels of essential fatty acid contents such as eicosapentaenoic acid (EPA) and docosahexaenoic acid (DHA).

\subsection{Experimental design and culture medium for live feed}

Three live feed microalgae (Nannochloropsis sp., Nannochlorum sp. and Tetraselmis sp.) species were cultured under indoor and outdoor condition in order to compare their growth in F2 media and inorganic fertilizer. F2 media is a stock solution prepared by mixing the chemicals according to [13]. For outdoor culture of microalgae, $0.5 \mathrm{ml} \mathrm{F} 2 \mathrm{medium} / 20$ L filtered seawater (25-30 ppt), inoculated with microalgae $\left(0.5 \times 10^{6} / \mathrm{ml}\right)$ applied at the rate of was $5-10 \%$ of culture volume. Light intensity was maintained from 1500 to 2000 lux for 24 hours with a constant temperature of $20-25{ }^{\circ} \mathrm{C}$. Duration of culture was 6-14 days. For mass culture of microalgae $\left(0.5 \times 10^{6} / \mathrm{ml}\right), 10-30 \%$ of total culture volume was inoculated in 200-2000 L of 25-30 ppt salt water for a period of 5-14 days under day-light photoperiod condition. Culture of live feed (microalgae and rotifer) were performed under the following experimental condition mentioned in Table 1.

Table 1 Experimental design for culture of live feed (microalgae)

\begin{tabular}{|c|c|c|c|c|c|c|}
\hline Treatment & Replications & Species & Protocol & Culture Vessel & Inoculums Density & Media \\
\hline $\mathrm{T} 1$ & 3 & Nannochloropsis $s p$. & \multirow{3}{*}{ Outdoor } & \multirow{3}{*}{$\begin{array}{l}\text { 300L white fibre } \\
\text { glass tank }\end{array}$} & \multirow{3}{*}{$0.5 \times 10^{6} / \mathrm{ml}$} & \multirow{3}{*}{$\mathrm{F} 2$} \\
\hline $\mathrm{T} 2$ & 3 & Nannochlorum $s p$. & & & & \\
\hline T3 & 3 & Tetraselmis $s p$. & & & & \\
\hline
\end{tabular}


For culture of rotifer, 15-20 ind./ml of culture volume was inoculated in 200-1000 L of 25-30 ppt salt water for a period of 7-10 days. Rotifers was fed with as per the design of experiment mentioned in Table 2. Harvesting of rotifer was done with 50-65 $\mu$ m plankton net.

Table 2 Experimental design for culture of live feed (rotifer).

\begin{tabular}{|l|l|l|l|l|l|}
\hline Treatment & Replication & Media/feeding & Protocol & Culture vessel & Inoculum Density \\
\hline T1 & 3 & Baker's yeast & & & \\
T2 & 3 & Microalgae & outdoor & 300L plastic jars & $20 / \mathrm{ml}$ \\
\cline { 1 - 3 } T3 & 3 & Yeast + microalgae & & & \\
\hline
\end{tabular}

\subsection{Nutritional Value of live feed (microalgae and rotifer)}

The nutritional value of any algal species for a particular organism depends on its cell size, digestibility, production of toxic compounds, and biochemical composition. Proximate composition of three microalgae species were analyzed from Bangladesh council of scientific and industrial research (BCSIR), science laboratory, Dhaka. The nutritional composition of microalgae species were done according to the protocol of [14]. On the other hand, nutritive value of rotifer (Brachionus sp.) enriched with different enrichments media were evaluated as per design described in Table 3.

Table 3 Experimental design for enrichment of rotifers (Brachionus sp.)

\begin{tabular}{|l|l|l|l|l|l|}
\hline Treatment & Replication & Media/feeding & Protocol & Culture vessel & Inoculum Density \\
\hline T1 & 3 & Microalgae & & & \\
T2 & 3 & Commercial diet & \multirow{2}{*}{ outdoor } & 300L plastic jars & $300-400 / \mathrm{ml}$ \\
\cline { 1 - 3 } T3 & 3 & Fish oil (Selco) & & & \\
\cline { 1 - 3 } T4 & 3 & Microalgae + fish oil & & & \\
\hline
\end{tabular}

Rotifer was cultured in baker's yeast, harvested and enriched with different enrichment media. After 6-8 hours of enrichment, rotifers were harvested further and the nutritive value (proximate composition and fatty acid contents) was investigated.

\subsection{Data Analysis}

The collected data and information has been statistically analyzed with MS Excel and presented as figures and tables to express the research findings in a meaningful way.

\section{Results and discussion}

\subsection{Growth performance of microalgae species cultured in outdoor condition}

For the microalgae species Nannochloropsis sp., Nannochlorum sp. and Tetraselmis sp. were cultured under outdoor condition. All three species started cell division immediately after inoculation and reached to the peak on 9 th day of culture. The stationary phase was observed for 9-14 days and then started to collapse. In outdoor condition highest average growth $6.87 \times 10^{6} \pm 1.97 \times 10^{6}, 6.91 \times 10^{6} \pm 1.69 \times 10^{6}$ and $6.23 \times 10^{6} \pm 1.53 \times 10^{6}$ was observed for Nannochloropsis sp., Nannochlorum sp. and Tetraselmis sp. respectively in trial 3. And lowest average growth $2.99 \times 10^{6} \pm 1.45 \times 10^{6}, 3.40 \times 10^{6} \pm 1.11 \times 10^{6}$ and $3.48 \times 10^{6} \pm 1.36 \times 10^{6}$ was observed for Nannochloropsis sp., Nannochlorum sp. and Tetraselmis sp. respectively (Table 4). The range of temperature: $20-30^{\circ} \mathrm{C}$; light intensity: 2500-8000 lux and salinity: 0-36 ppt. are generally used to culture Nannochloropsis oculata [15]. 
Table 4 Growth performance (cell/ml) of microalgae species under outdoor culture condition.

\begin{tabular}{|l|l|l|l|}
\hline Number of Trial & Nannochloropsis sp. & Nannochlorum sp. & Tetraselmis sp. \\
\hline Trial 1 & $2.99 \times 10^{6} \pm 1.45 \times 10^{6}$ & $3.40 \times 10^{6} \pm 1.11 \times 10^{6}$ & $3.48 \times 10^{6} \pm 1.36 \times 10^{6}$ \\
\hline Trial 2 & $4.99 \times 10^{6} \pm 2.08 \times 10^{6}$ & $5.01 \times 10^{6} \pm 1.68 \times 10^{6}$ & $5.08 \times 10^{6} \pm 1.62 \times 10^{6}$ \\
\hline Trial 3 & $6.87 \times 10^{6} \pm 1.97 \times 10^{6}$ & $6.91 \times 10^{6} \pm 1.69 \times 10^{6}$ & $6.23 \times 10^{6} \pm 1.53 \times 10^{6}$ \\
\hline
\end{tabular}

The optimal salinity is $22-25$ ppt. for $N$. oculata [16]. The microalgae culture condition of our study was within that range. All the microalgae species were collapsed sharply at 14th days of culture period. Growth performance of Tetraselmis sp. was highest in all trial with respect to other two microalgae species (figure 1). From figure 1 it is clearly observable that the order of growth pattern of three microalgae were Tetraselmis sp.>Nannochlorum

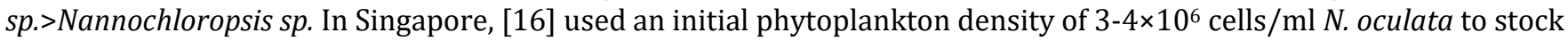
$3 \mathrm{~L}$ and $20 \mathrm{~L}$ bags. He found that culture of $3 \mathrm{~L}$ bags takes seven days, giving a final density of $2.00-2.50 \times 10^{7} \mathrm{cells} / \mathrm{ml}$ for $N$. oculata. He also found that $20 \mathrm{~L}$ cultures take five days to reach their maximum density of $1.80-2.00 \times 10^{7} \mathrm{cells} / \mathrm{ml}$.

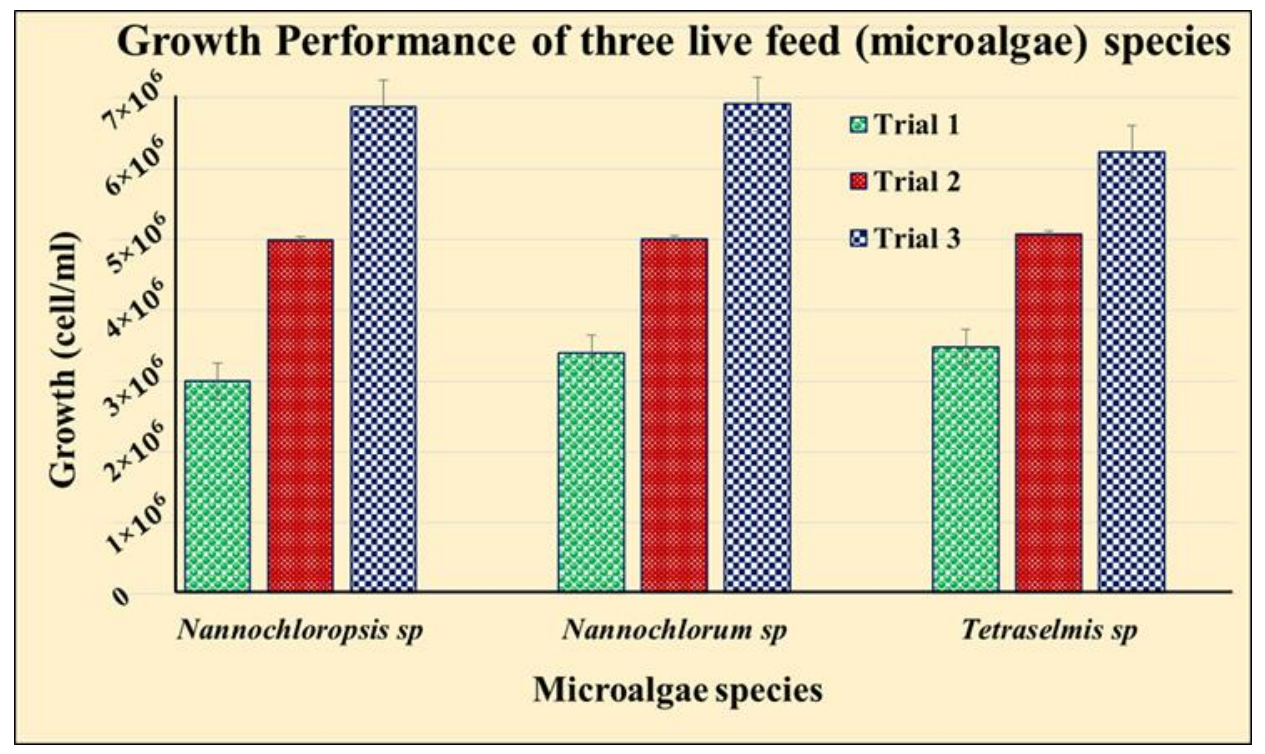

Figure 1 Growth Performance of three live feed (microalgae) under outdoor culture condition

\subsection{Growth performance of Rotifer (Brachionus sp.) in different medium}

Brachionus sp. was scaled up under outdoor culture condition in 300 liter plastic jars in $20 / \mathrm{ml}$ inoculum density with different media. Average growth of rotifer (Brachionus sp.) was highest $189 \pm 18.10 \mathrm{ind} / \mathrm{ml}$ at combined media of yeast and microalgae in trial 1 comparison with all treatment and trial (figure 2). Microalgae diet media yielded 158.33 \pm 21.60 , $148.33 \pm 15.60$ and $151.67 \pm 22.30 \mathrm{ind} . / \mathrm{ml}$ in trial 1 , trial 2 and trial 3 respectively, lowest growth rate was noticed with baker's yeast $119.67 \pm 17.60 \mathrm{ind}$./ml for trial 2 . In 300 liter plastic jars with $20 / \mathrm{ml}$ inoculum density, the growth performance of rotifer is better in the combined media of yeast and microalgae than microalgae diet and baker's yeast media. Growing rotifers (Brachionus plicatilis) at the temperature above $26^{\circ} \mathrm{C}$ and water salinity of $25 \mathrm{ppt}$ for optimum growth suggested by [17]. A density of 20 rotifer/mL of culture should be introduced and fed with baker's yeast at a rate of 0.25-0.50 g per million of rotifers twice a day [17-18]. For up-scaling culture, rotifers (Brachionus plicatilis) are solely fed by Nannochloropsis sp. from $100 \mathrm{ml}$ to $1000 \mathrm{~L}$ and inoculated about 10-20 rotifer/ml [19]. 


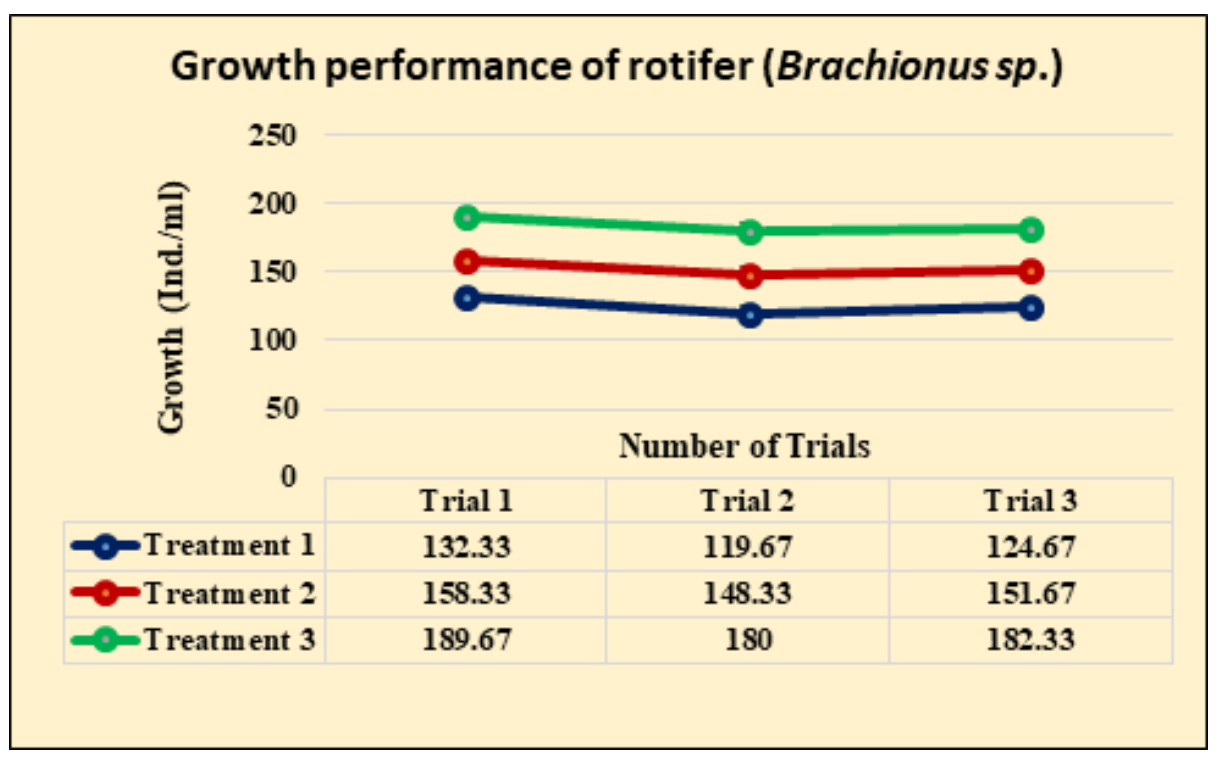

Figure 2 Growth performance of rotifer (Brachionus sp.) under different feedings.

\subsection{Proximate composition of live feed (microalgae)}

The nutritional value of any algal species for a particular organism depends on its cell size, digestibility, production of toxic compounds, and biochemical composition. The gross composition of three species of micro-algae is compared in Table 5. Although there are marked differences in the compositions of the micro-algal classes and species, protein is always the major organic constituent, followed usually by lipid and then by carbohydrate. Expressed as percentage of dry weight, the range for the level of protein, lipid, and carbohydrate are $18-18.20 \%, 60-63 \%, 10-18 \%$ and $9-12 \%$ respectively. Tetraselmis sp. contains highest level of protein content $63 \pm 0.05 \%$ followed by Nannochloropsis sp. and Nannochlorum sp. $(62 \pm 0.11$ and $60 \pm 0.09) \%$ respectively (Table 5). The highest lipid content obtained for Nannochloropsis sp. $18 \pm 0.02 \%$ followed by Tetraselmis sp. and Nannochlorum sp. $(11 \pm 0.02$ and $10 \pm 0.01) \%$ respectively. Nannochloropsis $s p$. contains maximum calories in $100 \mathrm{~g}$ dry weight of microalgae at a rate of $450 \pm 0.20$ followed by Tetraselmis sp. and Nannochlorum sp. $(390 \pm 0.18$ and $385 \pm 0.16) \%$ respectively (Table 5).

Table 5 Proximate composition of live feed (microalgae) cultured in outdoor condition.

\begin{tabular}{|l|l|l|l|}
\hline Parameters & Nannochloropsis sp. & Nannochlorum sp. & Tetraselmis sp. \\
\hline Dry Weight (\%) & $18.2 \pm 0.01$ & $18.0 \pm 0.02$ & $18.2 \pm 0.01$ \\
\hline Calories (100g dry wt. algae) & $450 \pm 0.20$ & $385 \pm 0.16$ & $390 \pm 0.18$ \\
\hline Protein (\%) & $62 \pm 0.11$ & $60 \pm 0.09$ & $63 \pm 0.05$ \\
\hline Lipid (\%) & $18 \pm 0.02$ & $10 \pm 0.01$ & $11 \pm 0.02$ \\
\hline Carbohydrate (\%) & $9 \pm 0.01$ & $12 \pm 0.01$ & $11 \pm 0.01$ \\
\hline Ash (\%) & $10 \pm 0.03$ & $12 \pm 0.04$ & $15 \pm 0.02$ \\
\hline Vitamin C (\%) & $0.85 \pm 0.01$ & $0.20 \pm 0.01$ & $0.25 \pm 0.01$ \\
\hline Chlorophyll A (\%) & $0.89 \pm 0.01$ & $1.40 \pm 0.01$ & $1.42 \pm 0.01$ \\
\hline
\end{tabular}

A considerable high protein percentage (62 and 55\%, d.w.), respectively, in Rhodomonas lens obtained in semicontinuous culture found by [20-21]. Whenever microalgae are used as a direct food source or as an indirect food source, in the production of rotifers, Artemia or copepods, growth of the animals is usually superior when a mixture of several microalgal species is used [22]. The dry matter composition of microalgae is highly variable, even within a given species, with protein contents ranging from $12-35 \%$, lipid from $7.2-23 \%$ and carbohydrates from 4.6-23\% [22]. Microalgae grown to late-logarithmic growth phase typically contain 30-40\% protein, $10-20 \%$ lipid and 5-15\% carbohydrate [23]. The findings of our study correlates with the finding of above mentioned literature. 


\subsection{Nutritive value of rotifer (Brachionus sp.) enriched with different enrichment media}

The nutritional value of rotifers for larval fish depends on the rotifer's food source. The feed of rotifers appears to the key element in their mass production as well as proximate composition. As in other zoo planktonic prey, rotifer biochemical composition is of primary importance for larval nutrition. The lipid and essential fatty acids profile is relatively modifiable by dietary manipulation [24-26]. Before the analysis of proximate composition the rotifer was enriched with different enrichment media as mentioned in methodology. The highest level of protein $56.3 \pm 0.18 \%$ found in rotifer enriched in combination with microalgae and fish oil followed by $51.4 \pm 0.29 \%, 40.5 \pm 0.23 \%$ and $38.5 \pm 0.83 \%$ for rotifer enriched with fish oil, commercial diet and microalgae respectively (Table 6). One the other hand, maximum lipid $28.5 \pm 0.16 \%$ found in rotifer enriched with fish oil followed by $24.6 \pm 0.22 \%, 22.6 \pm 0.27 \%$ and $21.2 \pm 0.19 \%$ for rotifer enriched with, commercial diet, microalgae+fish oil and microalgae respectively (Table 6).

Table 6 Proximate composition of live feed (rotifer) cultured in outdoor condition.

\begin{tabular}{|l|l|l|l|l|}
\hline Parameters & Microalgae & Commercial diet & Fish oil (Selco) & Microalgae + fish \\
\hline Protein (\%) & $38.5 \pm 0.83$ & $40.5 \pm 0.23$ & $51.4 \pm 0.29$ & $56.3 \pm 0.18$ \\
\hline Lipid (\%) & $21.2 \pm 0.19$ & $24.6 \pm 0.22$ & $28.5 \pm 0.16$ & $22.6 \pm 0.27$ \\
\hline Carbohydrate (\%) & $27.8 \pm 0.20$ & $24.3 \pm 0.10$ & $13.1 \pm 0.05$ & $11.8 \pm 0.08$ \\
\hline Ash (\%) & $7.9 \pm 0.08$ & $6.8 \pm 0.12$ & $3.06 \pm 0.04$ & $3.9 \pm 0.10$ \\
\hline Dry matter (\%) & $4.6 \pm 0.20$ & $3.8 \pm 0.20$ & $3.94 \pm 0.56$ & $5.4 \pm 0.10$ \\
\hline Moisture (\%) & $95.4 \pm 0.18$ & $96.2 \pm 0.15$ & $96.06 \pm 0.22$ & $94.6 \pm 0.20$ \\
\hline
\end{tabular}

According to [27], rotifer's protein content ranges between 28-63\%, lipid from 9- 28\%, and carbohydrate from 10.5 $27 \%$ of the dry weight (DW). Rotifer lipids have a high phospholipid content (34-43\% of total lipid), and $20-55 \%$ of triacylglycerols [27]. The mean protein level in rotifers fed with different types of feeds varied between $29.19 \pm 0.23 \%$ and $46.02 \pm 0.23 \%$ with the highest protein percentages in rotifers cultured with I. galbana (46.02 $\pm 0.23 \%)$ and the lowest protein level in rotifers fed Nannochloropsis sp. along with B. licheniformis (29.19 $\pm 0.23 \%$ ) reported by [28]. Protein content could vary with the type of food and growth phase and the values ranged from 34-52\% showed by [29]. A lower lipid level for rotifers fed with yeast alone and a lipid content of $13.1 \%$ along with Chlorella sp. for 24 hrs reported by [30]. Proximate composition of rotifer in our study correlates with the above mentioned literature.

\section{Conclusion}

From this experiment, it can be concluded that treatment $\mathrm{T}_{3}$ (yeast+microalgae) feeding media is advisable for rotifer production due to higher production and nutritional composition. Application of this findings might be developed the live feed production especially in the brackishwater hatcheries and extremely helpful for rearing of commercially important brackishwater finfishes and shellfishes.

\section{Compliance with ethical standards}

\section{Acknowledgments}

The authors would like to extend gratitude to Project Implementation Unit (PIU), National Agricultural Technology Program: Phase II Project Bangladesh Agricultural Research Council, Farmgate, Dhaka- 1215for providing financial support to successfully complete the research work.

\section{Disclosure of conflict of interest}

The authors declare no conflict of interest.

\section{References}

[1] Govoni JJ, Boehlert GW, Watanabe Y. (1986). The physiology of digestion in fish larvae. Environmental Biology of Fishes. 16: 59-77. 
[2] Lazo JP, Dinis MT, Holt GJ, Faulk C, Arnold CR. (2000). Co-feeding micro-particulate diets with algae: toward eliminating the need of zooplankton at first feeding in larval red drum (Sciaenops ocellatus). Aquaculture. 188 (34): 339-351.

[3] Cahu C, Infante JZ. (2001). Substitution of live food by formulated diets in marine fish larvae. Aquaculture. 200(12): 161-180.

[4] Koven W, Kolkovski S, Hadas E, Gamsiz K.U.T.S.A.L, Tandler A. (2001). Advances in the development of microdiets for gilthead seabream, Sparus aurata: a review. Aquaculture. 194 (1-2): 107-121.

[5] Holme MH, Zeng C, Southgate PC. (2006). Use of microbound diets for larval culture of the mud crab, Scylla serrata. Aquaculture. 257(1-4): 482-490.

[6] David AB. (2003). Status of marine aquaculture in relation to live prey: past, present and future. In: Josianne GS and Lesley AM (Eds.). Live feeds in marine aquaculture. Blackwell publishing, UK. 1-16.

[7] Evjemo J0, Reitan KI, Olsen Y. (2003). Copepods as live food organisms in the larval rearing of halibut larvae (Hippoglossus hippoglossus L.) with special emphasis on the nutritional value. Aquaculture. 227(1-4): 191-210.

[8] Harrison PJ, Thompson PA, Calderwood GS. (1990). Effects of nutrient and light limitation on the biochemical composition of phytoplankton. Journal of Applied Phycology. 2: 45-56.

[9] Tidwell JH, Schulmeister CM, Coyle S. (1997). Growth, survival, and Biochemical Composition of freshwater prawns Macrobrachium rosenbergii fed natural food organisms under controlled conditions. Journal of the World Aquaculture Society. 28(2): 123-132.

[10] Ohse S, Derner RB, Ozório RÁ, Corrêa RG, Furlong EB, Cunha PCR. (2015). Lipid content and fatty acid profiles in ten species of microalgae. Idesia. 33(1): 93-101.

[11] Whyte JMC, Nagata WD. (1990). Carbohydrate and fatty acid composition of rotifer, Brachionus plicatilis, fed monospecific diets of yeast or phytoplankton. Aquaculture. 89: 263-272.

[12] Das P, Mandal SC, Bhagabati SK, Akhtar MS, Singh SK. (2012). Important live food organisms and their role in aquaculture. Frontiers in aquaculture. 5(4): 69-86.

[13] Guillard RR. (1975). Culture of phytoplankton for feeding marine invertebrates. In Culture of marine invertebrate animals. 29-60.

[14] Brown MR, Jeffrey SW, Garland CD. (1989). Nutritional aspects of microalgae used in mariculture; a literature review. CSIRO Marine Laboratories Report. 205: 44.

[15] Hoff FH, Snell TW. (1987). Plankton culture manual. Florida Aqua farms. Inc. Dead City, Florida P. 126.

[16] Lim LC. (1991). An overview of live feeds production systems in Singapore. Rotifers and Microalgae Culture Systems. 203-20.

[17] FAO. (1996). Manual on the production and use of live food for aquaculture, FAO. Fisheries Technical Paper No. 361, ed. P. Lavens et al. (Food and Agricultural Organization of the United Nations, 618, Rome, 295.

[18] Islam ML, Islam MS, Yahya K, Hashim R. (2017). Effects of essential fatty acids containing natural and commercial diets on larvae rearing of the Green Mud Crab Scylla paramamosain (Estampador 1949). Journal of Scientific Research. 9(1): 09-126.

[19] Hagiwara A. (1989). Recent studies on the rotifer Brachionus plicatilis as a live food for the larval rearing of marine fish. La mer. 27: 116-121.

[20] Seixas P, Coutinho P, Ferreira M, Otero A. (2009). Nutritional value of the cryptophyte Rhodomonas lens for Artemia sp. Journal of Experimental Marine Biology and Ecology. 381(1): 1-9.

[21] Seixas P, Rey-Méndez M, Valente LM, Otero A. (2008). Producing juvenile Artemia as prey for Octopus vulgaris paralarvae with different micro algal species of controlled biochemical composition. Aquaculture. 283(1-4): 8391.

[22] Becker W. (2004). Microalgae for Aquaculture. Handbook of microalgal culture: biotechnology and applied phycology. 380.

[23] Brown MR, Jeffrey SW, Volkman JK, Dunstan GA. (1997). Nutritional properties of microalgae for mariculture. Aquaculture. 151: 315-331. 
[24] Ben-Amotz A, Fishler R, Schneller A. (1987). Chemical composition of dietary species of marine unicellular algae and rotifers with emphasis on fatty acids. Marine biology. 95(1): 31-36.

[25] Lubzens E., Zmora O, Stottrup J. McEvoy L. (2003). Production and nutritional value of rotifers. Live feeds in marine aquaculture. 1989; 300-303.

[26] Rainuzzo JR, Reitan KI, Olsen Y. (1997). The significance of lipids at early stages of marine fish: a review. Aquaculture. 155(1-4): 103-115.

[27] Lubzens E, Tandler A, Minkoff G. (2003). Rotifers as food in aquaculture. Hydrobiologia. 186(1), 387-400.

[28] Jeeja PK, Imelda J, Paulraj R. (2011). Nutritional composition of rotifer (Brachionus plicatilis, Muller) cultured using selected natural diets. Indian Journal of Fisheries. 58(2): 59-65.

[29] Caric M, Sanko-Njire J, Skaramuca B. (1993). Dietary effects of different feeds on the biochemical composition of the rotifer (Brachionus plicatilis, Muller). Aquaculture. 110: 141-150.

[30] James CM, Dias PA, Salman AE. (1987). The use of marine yeast (Candida sp.) and baker's yeast (Saccharomyces cerevisiae) in combination with Chlorella sp. for mass culture of the rotifer Brachionus plicatilis. Hydrobiologia. 147: 263-268. 